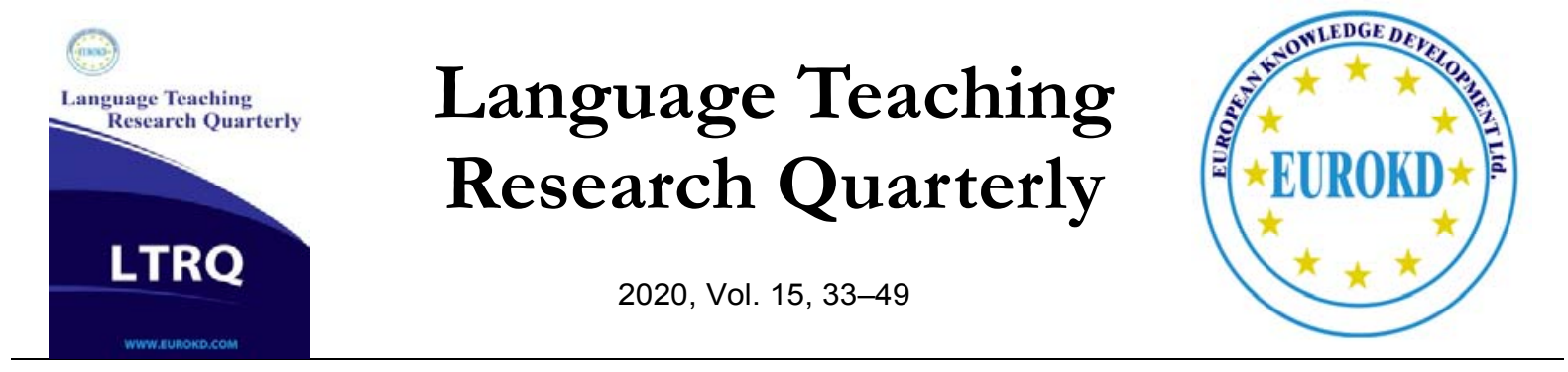

\title{
Materials Development in EALP Legal Writing Courses
}

\author{
Rafael Dean Brown*, Kashif Raza \\ College of Law, Qatar University, Doha, Qatar \\ Future Perspectives and Challenges of Materials Development \\ In Honor of Brian Tomlinson's Contribution to Materials Development Research
}

Received 12 August 2019 Accepted 29 November 2019

\begin{abstract}
While the field of materials development has grown in the past twenty years, covering areas like EAP and ESP, there remains a need to elaborate further the strategies and to develop a process for developing materials for EALP courses such as legal writing. Legal writing in particular poses unique challenges like the complex system of legal writing genres and the interferences created by multiple languages, cultures, and legal systems. This article expands on existing strategies offered by the scant literature on legal writing materials development. The article takes into account the work of materials development scholars who have proposed SLA-derived principles. The article also considers factors that affect materials development, including learner, teacher, and contextual factors. Additionally, the article considers the role of theoretical frameworks in shaping decisions in materials development. Most importantly, the article relies on methods in legal writing pedagogy to inform the strategies and process for legal writing materials development. The article ultimately proposes a process for developing materials for legal writing courses that requires the consideration of the (1) purpose, (2) audience, (3) course and curriculum requirements, (4) length and number of assignments, and (5) sociocultural and legal context of the materials
\end{abstract}

Keywords: Gender, Gender Representation, Textbook Analysis, Content Analysis, Image Analysis 


\section{Introduction}

Materials development is the study and practice of developing materials for the teaching of language, including the principles and processes of designing, implementing, and evaluating materials (Tomlinson, 2001). In the past twenty years, there has been a great increase in the literature on materials development (Tomlinson, 2010). There has been literature on materials development covering English for Academic Purposes (EAP) and English for Specific Purposes (ESP) courses (Tomlinson \& Masuhara, 2017; Lesiak-Bielawska, 2015). In ESP, for example, there is literature on materials development for business and technical English (Bielousova, 2017), science (Afitska, 2016), nursing, and adult English (Tomlinson \& Masuhara, 2017). One area of language learning that has received little attention from the field of materials development, however, is the teaching of legal writing, which involves language learning for L2 students of law for whom English is a second language. There is a need to develop a process of materials development for English for Academic Legal Purposes (EALP) courses such as legal writing. Materials development for L2 legal writing courses has also remained unexamined in legal writing scholarship.

This article discusses the theories, processes and challenges in materials development for legal writing courses taught to L2 students in both law school legal writing courses and non-law school ESP legal writing courses. The article begins by providing a background on Tomlinson's (2013) six principles for materials development, the use of contrastive rhetoric in legal writing courses for L2 students (Brown, 2005; Baldwin, 2104), and legal writing methodology. The article then identifies common challenges in materials development for legal writing courses. Next, the article discusses and adds to the strategies for developing materials for legal writing. Finally, the article proposes a process for developing materials for legal writing courses that incorporates the principles and strategies for materials development in legal writing.

\section{Principles, Factors, and Theories Affecting ESP Legal Writing Materials Development}

The authors have not found any standard process for developing legal writing materials for L2 students in both law school and ESP legal writing courses. Candlin, et al. (2002) did propose a set of strategies, which will be discussed further below, for developing materials for legal writing courses. Building on the work by Candlin, et al. (2002) this article aims to propose a process for materials development in EALP legal writing courses using a combined understanding of materials development and legal writing methods and pedagogy.

Before proposing a process for developing legal writing materials, it is important to consider existing principles of materials development in language learning. This section, therefore, provides a general background on the principles of materials development. Next, the section discusses factors that affect materials developments. Finally, this section discusses the theoretical frameworks that may later inform the decisions in materials development for L2 students. 


\section{Principles in Materials Development}

A lot has been written about the principles of materials development following the works of Brian Tomlinson, Ken Hyland and other researchers. Today, materials developers are comparatively more knowledgeable and better informed about the stages, rules and aims of materials development; however, a shared principle that has repeatedly been emphasized in this area is that language learning instructors should not base their decisions on the process for developing materials on random recreations or by recycling previously used materials (Tomlinson, 2010). Instead, there is a consensus in the literature that the development of materials should follow a principled approach with a defined objective (Hidalgo et al, 1995; Tomlinson \& Masuhara, 2011). The principles, according to Tomlinson, should be based on theory, teaching principles, knowledge of language use, and the result of a systematic observation and evaluation.

Tomlinson focuses on six principles that the developed materials should aim to achieve based on research in Second Language Acquisition (SLA) (Tomlinson, 2016). According to Tomlinson (2010), the materials should accomplish the following:

(1) "Expose learners to language in authentic use;

(2) Help learners to pay attention to features of authentic input;

(3) Provide the learners with opportunities to use the target language to achieve communicative purposes;

(4) Provide opportunities for outcome feedback;

(5) Achieve impact in the sense that they arouse and sustain the learners' curiosity and attention; and

(6) Stimulate intellectual, aesthetic and emotional involvement" (p. 82).

Since this article aims to provide a critic on the scant literature on materials development in EALP contexts and discuss related theories and principles, we do not discuss the six principles mentioned above in detail. Interested readers should consult Tomlinson (2010) for a detailed discussion. However, we emphasize that these principles cover significant aspects of SLA and outline important steps in developing effective materials for L2 learners.

\section{Factors in Materials Development}

The principles of materials development, however, are not the only points to consider. Scholars like Howard and Major (2004) and Richards $(2005,2006)$ have articulated factors to consider when developing materials. While Howard and Major (2004) identified six factors, Richards $(2005,2006)$ has succinctly categorized the factors into three main categories: learner, teacher, and contextual. Table 1shows a non-comprehensive list of factors that material developers should consider.

Table 1

Factors in Materials Development*

\begin{tabular}{lll}
\hline Learner Factors & Teacher Factors & Contextual Factors \\
Learner interests & Teacher's language proficiency & School culture \\
Language needs & Training and experience & Classroom conditions \\
\hline \hline
\end{tabular}




\begin{tabular}{lll}
\hline Learner motivations & $\begin{array}{l}\text { Cultural background } \\
\text { Learning style preference }\end{array}$ & $\begin{array}{l}\text { Class size } \\
\text { Pearner experience } \\
\text { Learner first language }\end{array}$ \\
$\begin{array}{l}\text { Cearner literacy } \\
\text { Learner purpose force and competence } \\
\text { language }\end{array}$ & $\begin{array}{l}\text { Time availability } \\
\text { Curriculum } \\
\text { Contextual purpose for learning }\end{array}$ \\
*Adopted from Richards (2005) and Howard and Major (2004). &
\end{tabular}

The learner factors listed in Table 1 are important in materials development because they address background, characteristics, purpose, and needs of the target audience for the materials. In ESP materials development, specifically, the purpose for learning the second language may be driven by the learner's desire to gain communicative competence as expected within a given field like medicine, business, or law. The list of teacher factors in Table 1 is just as important because the type of materials used will be determined by the teacher's abilities, experience, and preferences. Finally, materials development cannot ignore factors that are external to the teacherlearner relationship, but that set an environment or context for the learning to occur. The contextual factors in Table 1, therefore, includes classroom conditions, curriculum, and school resources and expectations.

\section{Theoretical Framework in Materials Development}

A theoretical framework is essential in understanding that the materials being developed are informed by relevant theories and concepts. Tomlinson (2010) contends that a framework assists in producing principled and organized materials that are effective and easy to develop. Additionally, material developers should contextualize the materials within the theoretical framework of language use, writing, and writing pedagogy. Hyland (2008) categorized these writing frameworks into three types: (1) text-oriented, (2) writer-oriented, and (3) readeroriented. The text-oriented theoretical framework views writing as outcome based. Within the text-oriented framework, the two most common approaches are (a) to view texts as objects with a focus on grammatical structures, and (b) to view text as discourse with a focus on the way language is used in particular situations. The writer-oriented framework, which views writing from the perspective of the writer rather than text, includes the expressivist and cognitivist approaches. While the expressivists focus on helping students achieve expressive competencies, the cognitivists focus on the writing process, using multiple edits to discover and arrive at meaning. Finally, the reader-oriented framework views writing as an interaction between the writer and reader, focusing on reader expectations and understanding the discourse community.

\section{Methods in Legal Writing Pedagogy Affecting Materials Development}

When developing materials specific to legal writing, it is important to consider methods in legal writing pedagogy. "Legal writing methods", which is the term we use to refer to a set of methods commonly used in legal writing pedagogy, should not be confused with the term "legal method", which refers to a set of techniques used to analyze and apply the law. While there is no universal standard for teaching legal writing, arguably the most dominant method for teaching legal 
writing arose from the U.S. law schools and U.S. legal writing scholarships, as recognized by Candlin, et al. (2002) in their review of available legal writing textbooks. The teaching of legal writing and the methods used for teaching legal writing globally has been largely influenced by the U.S. legal writing methods.

An overview of these methods reveals that the key features of a legal writing course include teaching the following components: (1) case summarizing, (2) legal methodology, (3) legal writing analytical structure, (4) case file method, (5) legal research, (6) memo writing, and (7) purpose specific legal writing. These methods have often been lumped and do fall into three main legal skills: analysis, research, and writing (Rowe, 2000). Lawyers and legal writing scholars view these three skill areas as intertwined and interdependent (Oates \& Enquist, 2014). From the authors' experience and a review of legal writing textbooks, these legal writing methods largely dictate the materials developed for legal writing courses (Burnham, 2006; Oates \& Enquist, 2014). Candlin, et al. (2002) described legal writing textbooks that are organized according to these methods as a "logical progression from a legal perspective" (p.308). What Candlin, et al. (2002) saw as logical progressions, however, are deemed essential components of a legal writing course among legal writing scholars (Oates \& Enquist, 2014).

A course on legal writing for L2 students usually requires introducing students to learn how to summarize a case, if that is not already covered in a separate course (Nedzel, 2007). Case summarizing is not so much a writing skill as it is about teaching students a methodical approach to read, comprehend, and analyze cases. While L1 students in U.S. law schools would normally learn how to summarize a case in their first semester of law school, L2 students whether in a U.S. or non-U.S. law school would have to be taught how to write a case summary in a legal writing course because they would not likely have had the skill taught to them previously. Case summarizing is an important skill in legal writing because legal writing courses normally use cases in legal analysis. An exception would be a very basic writing exercise in pure statutory application without the use of cases. The use of cases in legal analysis, however, has grown into a globally accepted method of legal analysis even in non-common law countries.

A legal writing course would also normally provide students with a background on the legal system or the legal methodology. For example, legal writing courses taught to L2 students in the U.S. would normally provide a background on U.S. legal methodology. Covering legal methodology in a legal writing course is essential in order to contextualize cases used in the class within a legal framework, and for students to understand the hierarchy of laws within a jurisdiction. Even in legal writing courses that use a hypothetical jurisdiction, teachers assume a specific set of legal methodologies like the use of stare decisis - a common law principle that means to stand by precedent (Burnham, 2006).

Students would have to be taught the CREAC method, which stands for Conclusory Statement, Rule, Explanation, Analysis, and Conclusion. CREAC is the legal writing method for organizing legal arguments. It has become standard in legal writing pedagogy to teach the CREAC method or any similar manifestation of the basic the legal writing analytical structure. The CREAC method essentially teaches students how to write the different features of a legal 
argument and the types of legal reasoning (Nedzel, 2007). A very simplistic way to explain the method is to teach students (1) how to write the answer to the legal issue posed, (2) how to write the rule, (3) how to write an explanation of the rule, and (4) how to write a legal analysis applying the rule to the facts. The CREAC method or similar structure has now become a common feature of legal writing and law school courses even outside the U.S. It remains unknown to the authors, however, and there seems to be no evidence of non-law school EALP legal writing courses teaching the CREAC method, the teaching of which seems limited to law school courses. Yet, the teaching of CREAC is essential because it drives the fundamental structure behind each type of legal analysis and pervades across different types of legal writing genres.

Legal writing courses typically use the case file method, which requires the use of a hypothetical case that provides the factual context from which the legal issue to be resolved arises (Oates \& Enquist, 2014). Case files can vary in length and complexity. They can be anywhere from a very short and simple paragraph summarizing the facts and legal context, or they can be very lengthy, sometimes exceeding 100 pages, and aim to mimic real life cases. A case file can contain all the needed legal resources (closed universe), or can be subject to further addition of legal resources found during legal research (open universe). The contents of a case file could also vary from a simple facts summary, to one that includes witness written, audio, or video testimonies and any variety of documentary evidence that could include sample agreements, emails, websites, or social media platforms, to name a few examples. In other words, the case file contents depend largely on the instructor's decision regarding materials development. When developing the case file materials, instructors should not be tempted to simply recycle old case files. From the authors' experience, it is standard practice among legal writing faculty to use a different case file each semester. However, because of the time it takes to create a new case file, instructors may be tempted to reuse old case files, and to keep the case file very basic. When developing case files, legal writing material developers should consider all possibilities to stimulate intellectual, aesthetic and emotional involvement (Tomlinson, 2016). For example, from the authors' experience, the use of social media imbedded in the case file has been very effective in this regard. An example is the creation and use of a fake Instagram account as part of the case file facts.

Legal writing courses usually require the teaching of legal research. Although legal research could be taught as a separate course, it is necessary to teach the role of legal research in legal writing and legal analysis. It should also be noted that legal research also requires the teaching of mini skills that includes, among others, search term writing in Boolean logic, case summarizing, reading skills, and incorporating legal research into legal texts.

The majority of legal writing courses use the memo method, where students are required to write either (1) an objective memo, or (2) a persuasive memo (Oates \& Enquist, 2014; Nedzel, 2007). In objective memo writing, students write legal memos that engage in an objective and predictive legal analysis of the potential outcome of a legal question within a given set of facts. 
In persuasive memo writing, students write memos that persuade a specific audience, usually a judge or an opposing counsel, to rule in favor of a given client's position. An introductory legal writing course normally covers the objective memo, and a more advanced course on persuasive memo writing follows. The standard view among legal writing scholars is that both types of memos are essential for students to learn. However, some legal writing courses for L2 students may only focus on one of these two types of memo due to time constraints. The memo method requires students to learn document level, rather than the CREAC paragraph level, legal writing organizational structures and conventions. Examples of the different organizational structures include (1) the client letter, (2) the interoffice memo, (3) the trial brief, (4) the appellate brief, and (5) court opinion (Oates \& Enquist, 2104). Each type of memo essentially requires learning a specific type of genre within legal writing. The legal context and methodology adopted in the course will certainly affect the choice of genre. It is important to provide students with opportunities to use the target language to achieve communicative competence (Tomlinson, 2016). In this sense, the use of the memo method is quite effective.

In addition to the general legal writing course, some legal writing courses, as a separate course or as an addition to the existing course, include teaching more specific legal writing skills like legal drafting or academic legal writing (Nedzel, 2007). In legal drafting, for example, students write legal agreements, legal instruments, and proposed statutory text. These specific legal writing genres require unique materials development considerations. For purposes of controlling the scope of this paper, the writers will focus only on materials development for general legal writing courses.

\section{Challenges in Materials Development for ESP Legal Writing Courses}

There are certainly a number of challenges when developing materials for a legal writing course. The challenges arise more specifically because the course is both a legal writing course and a language-learning course for L2 students. Particularly, the legal writing course is aimed at an L2 population that will likely consist of a group of students with multiple languages, competencies, cultures, and legal systems that then create diverse audiences who must learn different legal writing genres and skills used for various purposes, requiring the development of more than one type of materials. Let us discuss some of these challenges in detail to develop a better understanding of their nature and scope.

\section{Multilingual and Multicompetent Students}

Materials developed for an L2 legal writing course must address the needs of a multilingual and multi-competent student population with a diverse range of reading and writing competencies. One of the most germane challenges in developing materials for a multilingual and multicompetent student population is the diversity of writing and reading competencies. The materials developed must be able to address the range of student abilities. This means that the materials must not be too difficult for those with limited reading and writing abilities, while remaining engaging and challenging to students who are nearly fluent in English. Furthermore, developing 
the materials should take into account that some students may be multi-competent, not just in two, but in three or more languages. This is where the importance of L1 influence for developing legal writing skills becomes important, which is discussed in the next section. Material development should include a consideration of all of these factors for achieving effectiveness and relevance.

\section{Learning Interferences}

Additionally, the materials must address the learning interferences that arise due to varying language, rhetorical, cultural, and legal expectations from the first language. According to Brown (2005), there must be an explicit attempt to identify and understand the interferences carried over from the first language, culture, and legal systems to the second. McDaniels (1994) stated the need to explicitly identify the first language interference at the grammar and discourse level, while also addressing the "effects of different cultural 'logics' and 'realities' of discourse." In addition to the paragraph level, there are also differences in the grammatical expectations that interfere with learning the second language. For example, Arabic does not distinguish between capital and lower case letters, which can then cause students to ignore the rule in English and then write run-on sentences, or words and phrases that cause ambiguity in legal writing.

Most importantly, differently rhetorical expectations means that students may have different views on what constitutes a persuasive legal argument. Following research in contrastive rhetoric, what is persuasive in one culture is not necessarily persuasive in another, so a student must understand the rhetorical expectations of a given culture in order to formulate good persuasive arguments (Connor, 2002; Brown, 2005).

\section{Adopting Foreign Legal Methods}

A third challenge in materials development is to address the interference created when teaching in a different legal system than the one used in the materials, or when teaching in a mixed legal system. For example, the materials developed for a legal writing course may be based on a common law legal system but the course is taught in a country with a civil law or mixed legal system. As discussed above, the U.S. legal writing method has become the most dominant and influential method for teaching legal writing. However, adopting the U.S. legal writing method may create interferences with the different legal system. Unfortunately, the lack of available legal resources like publicly available cases, in countries like Qatar, for example, creates an even bigger challenge of not having a sufficient amount of legal resource materials available for pedagogical purposes. Therefore, the U.S. legal resources and legal writing methods may be employed as the best alternative.

However, if the legal materials used are anchored to a second legal system like the U.S., learning interferences will likely arise because of assumptions students make about the second legal system based on their knowledge of the first legal system. (Brown, 2014). For example, when students at Qatar University College of Law (QU Law) are taught using New York law, they will not understand how New York state law differs from federal law because Qatar is not a 
dual federal system. Such differences in the legal system, must be explicitly taught to students to avoid learning interferences.

\section{Student Needs}

Another challenge is to make sure that the materials developed are sensitive to the needs of students who will read and engage with the materials. Student needs could be defined by learner factors described above such as interests, motivations, purpose for learning a second language, first language, experience, literacy, or style preference. In L2 legal writing classrooms, understanding student needs poses a substantial challenge to the material developer. Some legal writing classrooms may include students from multiple legal, linguistic, cultural, social, or even educational backgrounds. The materials must be able to adapt to the diversity of the potential learner.

Student will likely engage with the materials from a different socio-cultural lens. The content and language of the materials developed must not offend socio-cultural and traditional notions of any given learner. Doing so would not only risk raising complaints from students, but most importantly, discourage students from engaging with the materials and the class as a whole. This concern is consistent with the principles laid out by Tomlinson (2016) that the materials should "arouse and sustain the learners' curiosity and attention"; and "stimulate intellectual, aesthetic and emotional involvement."Materials that are insensitive to the socio-cultural context will not likely stimulate intellectual and emotional involvement, but may lead to the disinterest in the course. What is most important with regards to materials development is to create materials that do not create an added distraction to an already challenging audience and socio-cultural context.

\section{Legal Writing Genres}

Finally, a fifth challenge is to ensure that the materials developed are able to help build on L2 students' writing and reading competencies within and among the genres of legal writing. There are two types of challenges related to legal writing genres: bridging legal and non-legal writing genres, and teaching the systems of genres within legal writing.

First, the materials must be able to identify and address interferences between non-legal writing genres and legal writing genres. Since legal writing uses specific language and rhetorical devices common within legal writing, the legal writing materials must be able to bridge the gap between what students learned in non-legal writing course and the common legal writing genrespecific expectations. For example, students need to learn that the CREAC paragraph structure, road mapping, signposting, and the persuasive use of legal citations, among others, are standard in legal writing, though not necessarily in non-legal writing courses. These rhetorical and linguistics features of the legal writing genre must be taught to students (1) who already habitually rely on non-legal writing expectations, and (2) have already developed legal writing techniques from their first language. However, the materials should also teach students that the legal writing methods like the CREAC structure, evolved from non-legal writing paragraph structures of Introduction, Body, and Conclusion. 
Second, the materials must be able to teach the multiple types of legal writing genres, while showing how these genres are interrelated or interdependent. While one challenge is to decide which set of legal writing genres would be appropriate for the course, another challenge is how to present them so that the students appreciate the relationships. While such a decision may be affected by course and curriculum requirements, ultimately, the instructor will still have to decide what genre is most appropriate taking into account the principles, factors, and theoretical frameworks for material development. The scaffolding approach could be a useful tool in developing materials that build on a set of learning outcomes of progressively increasing level of difficulty. For example, case summarizing could be the easiest level, which helps the student write a client letter using the same case summary, which then helps the student write an objective memo analyzing multiple cases addressing a specific legal issue for the same client.

Material developers for legal writing courses should recognize that the teaching of legal writing means teaching the multiple genres of legal writing. The challenge is to make the proper decision on which genres to include, how to connect the chosen genres linguistically and discursively, and to incorporate EALP research and materials development principles into the development of materials, as Candlin, et al. (2002).

\section{Strategies for Legal Writing Materials Development}

Candlin, et al. (2002) are among the very few scholars to have conducted an analysis of legal writing materials for L2 students. Their study found existing legal writing textbooks to be insufficient for L2 students because they focus either on L1 students or "on a narrow EALP context, such as a specific country, program, or purpose" (Candlin, et al., 2002, p.306). It should be noted, however, that since the article by Candlin, et al. (2002), legal writing textbooks that aim to address the needs of L2 students have been published, including by Nedzel (2007), Ramsfield (2005), McGregor and Adams (2008). However, these books are not grounded sufficiently on evidence-based linguistic and discursive analysis of legal language, and research from SLA and materials development.

In their article, Candlin, et al. (2002) made three suggestions regarding the development of legal writing materials for L2 learners. First, they suggest developing legal writing materials that are customized to L2 learners by using (1) pedagogical techniques that employ a variety of effective rhetorical devices like exercises, diagrams, figures, illustrations; (2) interactive and learner focused materials like task-based exercises, role playing, or simulation; and (3) a teacher manual or guideline. Second, they suggest developing materials for legal writing that are based on legal language and legal discourse by (1) grounding the materials on language learning research like SLA research, (2) teaching learner how to engage in the legal discourse community, (3) using a research driven legal writing genre-based approach, and (4) focusing in legal language rather than content. Finally, they encourage the creation of a materials bank, suggesting that legal writing textbooks are not enough.

We agree largely with the strategies proposed by Candlin, et al. (2002). The use of rhetorical devices is consistent with Tomlinson's principle of arousing the students' curiosity and attention 
during the learning process. The use of a learner centered and interactive materials is consistent with Tomlinson's principle on the need to stimulate the intellectual, aesthetic and emotional involvement of the student. Also, developing materials that promote participation in the legal discourse community is consistent with Tomlinson' principle of exposing students to the authentic use of legal language. We also agree with the strategy of developing materials that is genre-based, research-based, and language focused. We further suggest creating genre-based materials that employ the scaffolding approach (Hyland, 2008) to create continuity in language and discourse capacity, and that encourage confidence building in the learner (Tomlinson, 2010).

Another way of conceptualizing the strategies for developing materials that evolve around a learner-centered pedagogical strategy is to create materials that follow what we call the four $\mathrm{R}$ strategy: (1) relatable, (2) relevant, (3) resourceful, and (4) responsive. We will discuss these strategies in detail below.

\section{Relatable}

Being relatable means that students understand the processes described in the materials and the class so that they can share in the responsibility of the class, which leads to self-efficacy and confidence building. There is sufficient literature in the need to develop humanizing materials (Tomlinson \& Matsuhara, 2018). Materials development should create materials that help in the pedagogical aim of creating and maintaining a humanizing environment in the classroom. Features of a humanizing environment are (1) shared decision-making with students (i.e. having students contribute to the materials developed for the class), (2) fairness and transparency in the use of teaching and assessment materials (i.e. explaining to the students ahead of time what they are expected to learn and the rubrics for the assessment), and (3) cooperative learning (i.e. encouraging group work around the materials) (Bloom, 2013). A humanizing environment encourages the personal growth of students through shared responsibility in engaging with and learning from the materials, allowing the student to relate to the materials and to each other's experiences with the materials.

At the beginning of each semester, we address cultural and language interferences through the use and explicitly teaching of contrastive rhetoric, which aims to help students be aware of learning interferences that arise from culture, language, and legal systems. An example is to discuss and compare the role of a lawyer in general and the role of a lawyer as a writer in two given cultures. Developing materials that are relatable means that the materials must help the students develop self-efficacy and build confidence.

\section{Relevant}

Developing relevant materials means showing students the importance of the skills taught with the materials, not only for use while they are in law school, but in their life and careers (Hyland, 2008; Tomlinson, 2010). To make the materials developed for the course relevant to students, the materials must be process focused, and not outcome focused. Students must appreciate that the materials are about not only determining grades, but more importantly about teaching skills that 
will help them beyond law school. What students ultimately take away from the class materials are a number of mini skills that are not only very important in legal writing, but can also help them in making non-legal and sometimes personal decisions.

\section{Resourceful}

Developing resourceful materials requires the use of whatever means are available to make the materials more engaging. The materials must embrace the use of technology. The materials are, therefore, "technology-assisted" materials. Technology will never replace good teaching strategies and standard legal writing materials, but technology can assist and make the materials more engaging to already tech-savvy students. The materials developed uses both Prezi and PowerPoint. Prezi is a presentation platform that allows for a three dimensional representation of ideas. The materials also integrate social media platform like Instagram, and encourage students to use technology to enhance learning. Additionally, the materials developed uses stories from children's tales like Little Red Riding Hood, YouTube videos, sample real cases and clients as anecdotal evidence, pop-culture, movies, and everyday scenarios to help explain complex legal writing concepts.

\section{Responsive}

Developing "responsive" materials, to borrow a word from web-designers, means to create materials that respond to the specific needs of each student regardless of the student's background. The material developed should teach to all learning styles. Most importantly, the materials developed must be adaptable to the diversity of students who are multicultural and multi-competent with varying degrees of reading and writing competencies. Adaptability means that the materials should anticipate the varying levels of competence and teach to all the levels.

For example, we make the materials both visual and auditory by using Prezi that are sometimes embedded with a YouTube video or a website. Materials are developed with active learning in mind and engaging students in actual research. The materials developed must get students involved in a conversation. Also, exercises can be created that are tailored to the specific writing challenges of students. These errors can be spotted with a benchmarking writing assessment at the beginning of the course.

\section{Proposed Process of Legal Writing Materials Development}

Keeping in mind the strategies discussed previously, we propose a process for developing materials for legal writing courses that consists of considering the (1) purpose, (2) audience, (3) course and curriculum requirements, (4) length and number of assignments, and (5) sociocultural and legal context of the materials. We propose this process keeping in mind SLA best practices as articulated by Tomlinson, factors in materials development, and common methods in legal writing pedagogy. Most importantly, it should be noted that the instructor's theoretical preferences also affect the process for material development. 


\section{Purpose of the Course and Materials}

Considering the purpose requires knowing the type of legal writing course for which the materials are being developed. As discussed above, there are different types of legal writing courses and genres. Legal writing can generally be divided into objective memo writing, persuasive memo writing, and legal drafting.

The purpose of the legal writing course will largely determine the type of materials and the process for developing the materials. The difference in the purposes of the courses, for instance, affects the types of case file, cases, and supplementary materials that need to be developed. One important aspect of the purpose consideration is to provide students with samples so that they are aware of the purpose as well. It is important here that the materials will help students see the features of an authentic legal writing input for the purpose of the legal writing genre (Tomlinson, 2016). Therefore, the materials should include a sample persuasive memo to demonstrate what an authentic persuasive memo should look like.

Aside from the purpose of the course, the purpose of the materials to be developed should also be considered. Each type of material may be developed to provide factual or legal background or context, for specific legal skills or professional development purposes, for factual review, to trigger legal analysis and structures of legal argumentation, to conduct a case summary exercise or review, assessment, to provide a sample, or to trigger self-reflection, among others. The purpose of the material within the course, curriculum, and learning objectives will affect the type and content of the materials.

\section{Audience of the Course}

Legal writing courses in the U.S. have traditionally been taught to L1 students in Juris Doctorate programs of the U.S. law schools, and initially did not require an audience analysis for materials and course development. In the past ten years, however, students in the U.S. law schools have become more internationally and culturally diverse, multi-competent, and multi-jurisdictional (or with competence in more than one legal system) (DeLisle, 2014; Tobenkin, 2009). Therefore, even legal writing courses in the U.S. now need to consider the audience for the course when developing materials.

The need for considering the audience is even more germane when teaching legal writing courses primarily aimed at L2 students, and when teaching to students in a non-U.S. law school. This is the case, for example, when teaching legal writing in English to students at Qatar University College of Law, where students are multi-competent L2 law students with varying levels of English proficiency in a gender segregated classroom, the majority of whom are native Arabic speakers.

Keeping the socio-cultural as well as linguistic backgrounds of the learners that often affect their language development processes (Raza, 2018), the materials developed should be flexible and accessible to students with varying levels of language competence. Also, the materials must be culturally, socially, and religiously aware and responsible. As stated by Tomlinson (2016), 
cultural sensitivity should also be taught, practiced, and imbedded in the materials development process.

\section{Formal Course and Curriculum Requirements}

Materials development also requires considering the curriculum and educational objectives of the legal writing course. This is consistent with the contextual factors identified by Howard and Major (2004) and Richards (2005, 2006). School curriculum requirements may dictate, for example, the type of legal writing genre or memo that the course should address. Additionally, the material developer should consider the length and level of the course. While some legal writing courses are aimed for L2 students studying in an LLM program at a U.S. law school, some are aimed at L2 students in non-U.S. law schools with different course and curriculum requirements. Furthermore, a number of ESP legal writing courses are taught at the pre-law school level, or as prerequisites to the law school legal writing courses. These pre-law school legal writing courses will have to make specific decisions about the learning objectives of the course that is consistent with the law school courses students are being prepared for, keeping in mind legal writing methods and principles of materials development.

Materials development requires determining the course content. As a legal writing course, materials must include a hypothetical case file that students "solve", and which becomes the driver of the main writing components of the course. The development of the hypothetical case file materials is an opportunity to allow the materials to expose students to legal language in its authentic use (Tomlinson, 2016).

Based on the case file, students will write formal legal analysis using a CREAC paragraph structure. While the course is on legal writing, it becomes essential to teach students specific key legal skills in conjunction with the teaching of legal writing. Examples of key legal skills that may be explicitly taught concurrently in a legal writing course include (1) case reading, (2) case summarizing, (3) case analysis, (4) issue spotting, (5) rule identification, (6) rule synthesis, (7) professionalism, (8) search term generation, (9) legal research, (10) rule hierarchy, (11) legal methodology, (12) civil procedure, (13) common law and civil law systems, (14) persuasive storytelling, and (15) oral arguments (Oates and Enquist, 2014).Here, the genre-based approach could be used with the scaffolding approach to create materials that interrelate at the linguistic and discourse level. Again, material developer should keep in mind that materials should be responsive to the diverse needs of the learners.

\section{Length and Number of Writing Assignments}

Another consideration in material development for a legal writing course is the length and number of writing assignments. The majority of legal writing faculty assign multiple legal memo assignments throughout a semester, while some assign one legal memo that the students work on the entire semester. The length of the memo can vary from two to thirty pages depending on the number of legal memo assignments assigned. Traditionally, objective memo courses assign three to four memo writing assignments ranging at an average of eight to ten pages per assignment, 
while the persuasive memo courses assign one to two memo writing assignments ranging at an average of twenty to thirty pages per assignment.

Legal writing courses with L2 students may choose to assign a lower number of, and shorter, memo writing assignments. However, material developers should keep in mind that giving less reading materials is not necessarily the best decision. What is most important is to strike a balance of challenging students with a sufficient amount of writing assignments but not to the point where they are discouraged. Students, however, will engage with the materials more if they develop confidence (Tomlinson, 2016). The writing process scaffolding approach could be helpful in this regard (Heyland, 2008).

According to Tomlinson (2016), the materials should provide opportunities for outcome feedback. Along the same lines, the scaffolding approach would be more effective if coupled with effective outcome feedback mechanisms at each stage or level of difficulty. Failure to provide feedback at each stage of the scaffolding, based on our experience, could lead to the teacher making assumptions about the students' confidence and readiness to move up to the levels of the scaffolding. In legal writing courses for L2 students, a combination of both written and oral feedback is most effective based on years of experience, and systematic observation and evaluation of students' interaction with materials.

\section{Sociocultural and Legal Context of the Materials}

Finally, developing materials for a legal writing course requires considering the sociocultural and legal context where the course is being taught. In so doing, the legal issues, cases, and facts included in the materials should be sensitive to the sociocultural needs of the students as well as to the legal context.

Sociocultural sensitivity means that the materials should aim to predict interferences caused by cultural, language, and rhetorical expectations from the first to the second culture and language. Consideration should be given at both the grammatical and discourse levels. Additionally, the materials should strive to achieve a balance between sociocultural sensitivity while retaining the ability to arouse and sustain the students' interest and engagement (Tomlinson, 2016).

Additionally, the materials should consider the interferences created when the materials are based on a second legal context that differs from the legal context of which the student practices or is familiar with. If the materials require the use of multiple legal systems, the materials should explicitly identify and help students to understand the cross-legal interferences.

\section{Conclusion}

Developers of legal writing materials should consider the SLA principles, factors, and theoretical frameworks. It is also equally important to consider and understand the necessity to incorporate commonly accepted legal writing methods, which play important roles in developing the three key aspects of legal writing pedagogy: writing, research, and analysis. It is only after considering both the legal writing and the L2 writing components that we can fully appreciate the challenges 
in developing legal writing materials. We build on previously proposed strategies by integrating principles developed in materials development and SLA literature, and offer a reconceptualization of the strategies using a student-centered approach to develop materials that are relatable, relevant, resourceful, and responsive. In the end, we rely on the strategies and principles in materials development to propose a process for developing materials for a legal writing course.

\section{References}

Afitska, O. (2016). Scaffolding learning: developing materials to support the learning of science and language by non-native English speaking students. Innovation in Language Learning and Teaching, 10 (2), 75-89.

Baldwin, E. (2014).Beyond contrastive rhetoric: Helping international lawyers use cohesive devices in U.S. legal writing. Florida Journal of International Law,26, 399.

Bielousova, R. (2017). Developing Materials for English for Specific Purposes Online Course within the Blended Learning Concept. TEM Journal,6, (3), 637-642.

Bloom, E. (2013). Teaching Law Students to Teach Themselves: Using Lessons from Educational Psychology to Shape Self-Regulated Learners. Wayne Law Review, 59, 311.

Brown, R. (2005). Using contrastive rhetoric in legal writing pedagogy. Proceedings from GLSC 2005:First Global Legal Skills Conference. Chicago, Illinois: John Marshal Law School. Retrieved from: https://www.researchgate.net/publication/321275113 Using_Contrastive_Rhetoric_in_Legal_Writing_Pedago gy

Burnham, W. (2006). Introduction to the law and legal system of the United States(4th ed.).Minnesota, USA: West Publishing.

Candlin,C., Bhatia, V., and Jensen. C. (2002). English for Specific Purposes, 21, 299-320

Connor, U. (2002).New directions in contrastive rhetoric. TESOL Quarterly,36(4), 494-510.

DeLisle, J. (2014). The Internationalization of Professional Education: Lessons from Law School and China. Presented at the Internationalization of U.S. Education in the 21st Century: The Future of International and Foreign Language Studies. College of William and Mary, Williamsburg Virginia. Retrieved from https://www.wm.edu/offices/revescenter/globalengagement/internationalization/papers\%20and $\% 20$ presentatio ns/jacquesdelisle.pdf.

Hyland, K. (2008). Writing theories and writing pedagogies. Indonesian Journal of English Language Teaching,4 (2), 91-110.

Howard, J., \& Major,J. (2004). Guidelines for designing effective English language teaching materials. Proceedings from PAAL '9: Conference of Pan-Pacific Association of Applied Linguistics. Kanagawa, Japan: PAAL. Retrieved fromhttp://www.paaljapan.org/resources/proceedings/PAAL9/pdf/Howard.pdf.

Lesiak-Bielawska, E. (2015).Key Aspects of ESP Materials Selection and Design. English for Specific Purposes World, (46).

McDaniel, B. (1994). The role of contrastive rhetoric in teaching professional communication in English as a second or foreign language. IEEE Transactions on Professional Communication,37, (1), 29-33.

McGregor, D. B., \&Adams, C. M. (2008).The international lawyer's guide to legal analysis \& communication in the United States. New York: Aspen Publishing.

Nedzel, N. E. (2012).Legal reasoning, research and writing for international graduate students (3rd ed.).New York: Aspen Publishing.

Oates, L. C.,\& Enquist, A. (2014). The legal writing handbook: Analysis research and writing(6th ed.). New York: Aspen Publisher. 
Ramsfield, J. J. (2005).Culture to culture: A guide to U.S. legal writing. North Carolina: Carolina Academic Press.

Raza, K. (2018). Adapting teaching strategies to Arab student needs in an EFL classroom. Journal of Ethnic and Cultural Studies, 5 (1), 16-26.

Richards, J. (2006). Materials development and research - making the connection. RELC Journal, 37 (1), 5-26.

Rowe, S. (2000). Legal Research, Legal Writing, and Legal Analysis: Putting Law School into Practice. Stetson Law Review, 29, 1193.

Tobenkin, D. (2009). Legal Minds: Internationalization is expanding rapidly at law schools. International Educator. Retrieved from https://www.nafsa.org//File//janfeb09 feature legalminds.pdf

Tomlinson, B. (2001). Materials development. In R. Carter \& D. Nunan (Eds.), The Cambridge guide to teaching English to speakers of other languages (pp. 66-71). Cambridge: Cambridge University Press.

Tomlinson, B. (2010). Principles and procedures of materials development. In N. Harwood (Ed.) Materials in ELT: Theory and practice (pp. 81-108). Cambridge: Cambridge University Press.

Tomlinson, B. (2012). Materials development for language learning and teaching. Language Teaching, 45(2), 143179.

Tomlinson, B. (Ed). (2013).Developing materials for language teaching(2nd ed.). Cambridge: Cambridge University Press.

Tomlinson, B. (2016). The importance of materials development for language learning. In M. Azarnoosh, M. Zeraatpishe, A. Faravani \& H. R. Kargozari (Eds.), Issues in materials development (pp. 1-10). Rotterdam: Sense Publishers.

Tomlinson, B. \& Masuhara, H. (Eds.) (2011).Research for Materials Development in Language Learning: Evidence for Best Practice. London: Continuum.

Tomlinson, B. \& Masuhara, H. (2017).The Complete Guide to the Theory and Practice of Materials Development for Language Learning. Hoboken: Wiley-Blackwell. 